\title{
Assessment of Clinical Features and Morphological Characteristics of Myocardial Bridging Involving the Left Circumflex Artery Using Coronary Computed Tomography Angiography
}

\author{
Peipei Wang \\ Shanghai University of Medicine and Health Sciences Affiliated Zhoupu Hospital \\ Ming-Yuan Yuan ( $\nabla_{\text {zp_yuanmy@sumhs.edu.cn ) }}$ \\ Shanghai University of Medicine and Health Sciences Affiliated Zhoupu Hospital https://orcid.org/0000-0002-7882-0311
}

\begin{abstract}
Research Article
Keywords: Myocardial bridging, Left circumflex artery, Coronary computed tomography angiography, Fractional flow reserve, Coronary dominance
\end{abstract}

Posted Date: February 24th, 2022

DOI: https://doi.org/10.21203/rs.3.rs-1332186/v1

License: @ (1) This work is licensed under a Creative Commons Attribution 4.0 International License. Read Full License 


\section{Abstract \\ Purpose}

This retrospective study aimed to investigate the clinical features and morphological characteristics of myocardial bridging involving the left circumflex artery and its branches using coronary computed tomography angiography.

\section{Methods}

We enrolled 23 patients (mean age: $55.65 \pm 13.28$ years) with myocardial bridging of the left circumflex artery between January 1, 2014 and July 31,2020 . All patients underwent coronary computed tomography angiography and electrocardiography. The morphology, clinical findings, and coronary computed tomography angiography -derived fractional flow reserve were compared for patients with myocardial bridging of a single left circumflex artery $(n=23)$, right coronary artery $(n=10)$, and left anterior descending artery $(n=23)$.

\section{Results}

Myocardial bridging of the left circumflex artery were more commonly superficial (superficial myocardial bridging: 22 vs. deep myocardial bridging: 1) while bridging in the left anterior descending artery was mostly located in the middle segment $(91 \%, 21 / 23)$, and bridging in the left circumflex artery was mostly located on the distal-segment or obtuse marginal branch $(87 \%, 20 / 23)$. The $95 \%$ confidence interval of myocardial bridging thickness, myocardial bridging length, arterial diameter in systole and diastole period of the myocardial bridging of the proximal segment was: $0.24(0.05,0.43), 2.88(2.32,3.42), 1.67(1.47,1.87)$, and $1.74(1.54,1.95)$, respectively. $95 \%$ confidence interval of computed tomography-derived fractional flow reserve in the proximal and distal segments of bridging were $0.96(0.96,0.97)$ and $0.93(0.92$, $0.94)$, respectively. All heart dominance showed right coronary dominance $(73.91 \%, 17 / 23)$ or co-dominance $(26.09 \%, 6 / 23)$.

\section{Conclusions}

All patients with bridging segments in the left circumflex artery have right coronary dominant or co-dominant hearts. Bridging of the left circumflex artery is mostly long and located in the distal segment. Computed tomography-derived fractional flow reserve showed a low value in diagnosing myocardial ischemia resulting from myocardial bridging of the left circumflex artery.

\section{Introduction}

Myocardial bridging (MB) is a congenital anomalous coronary disease that is defined as a segment of the coronary artery covered by myocardial fibers. MB is generally considered to be a benign disease as most patients are asymptomatic. However, some researchers have recently identified that $\mathrm{MB}$ can cause angina, coronary syndrome, and severe cardiac events [1-4]. Most MBs involve the left anterior descending (LAD) artery, followed by the left circumflex (LCX) artery, right coronary artery (RCA), and other small branches, such as the diagonal artery, ramus intermedius artery, and obtuse marginal branch (OM) artery $[5,6]$. Multiple investigations have reported on the morphology and clinical features of MB located on the LAD artery; however, a few case reports have described symptomatic cases in which MB involved the LCX artery [7-14], and almost all of these patients underwent conventional coronary angiography. No studies describe the clinical features and morphological characteristics of bridges in the LCX artery; especially the change of hemodynamics in the bridging segment. Therefore, this study aimed to assess the value of clinical findings, morphological characteristics using coronal computed tomography angiography (CCTA), and hemodynamic changes in MB of the LCX artery using computed tomography-derived fractional flow reserve (CT-FFR) and the CCTA.

\section{Methods}

\section{Population study}

This retrospective study included 8,375 patients with MB, who were diagnosed using CCTA between January 1, 2014, and July 31, 2020, from the Picture Archiving and Communication System at our center. We selected 100 patients with bridging of the LCX artery. Among them, only patients with isolated MB involving the LCX artery and its branches were enrolled in the study. The exclusion criteria were as follows: 1) MB associated with atherosclerosis and other cardiovascular diseases, 2) MB associated with pulmonary artery disease, 3) MB associated with structural heart disease, 4) Poor quality CCTA images that affect the diagnosis, 5) MB associated with abnormal coronary artery origin, 6) MB involving both LCX and non-LCX coronary artery branches. A flow chart of the data filtering process is illustrated in Fig. 1 . Finally, 17 patients 
with MB of the LCX artery, 5 patients with MB of the OM branches, and 1 patient with MB of both the LCX artery and OM branches were included in the study. In addition, 23 cases of isolated MB of the LAD artery were selected randomly according to the age- and sex-matched methods, while 10 patients with MB of the RCA were included in the control group. Duplicate cases were not included, and information regarding general characteristics like the name, age, and sex of the patient was kept hidden by the author (PP. W) to protect patient's privacy. This study has been approved by the hospital ethics committee.

The length, depth, and location of the MB along with the electrocardiogram (ECG), CT-FFR of the proximal and distal segments of the bridging, and other clinical findings were analyzed. The MB length was defined as the curve distance from the start to the end of the MBs. The MB depth was defined as the maximum thickness of the myocardial fibers covering the tunnel coronary artery. Superficial and deep MBs were defined as an $\mathrm{MB}$ depth of $<2 \mathrm{~mm}$ and $>2 \mathrm{~mm}$, respectively. To explore the relationship between heart dominance and the location of $\mathrm{MB}$, we retrospectively enrolled 100 patients out of 8,375 patients with MB of the LCX artery and its branches, including those associated with other cardiovascular diseases.

\section{Ct Protocols}

All imaging data were acquired using GE Revolution CT (GE Healthcare, Little Chalfont, UK). The nurses adhered to the standard operating procedures, including embedding indwelling needles in the vein and imparting breathing training, before scanning. The scanning parameters were set as follows: 1) The tube voltage and tube currents were $120 \mathrm{KV}$ and $34 \mathrm{~mA}$, respectively. 2) The tube thickness was set at $1.25 \mathrm{~mm}$ with a $2 \mathrm{~mm}$ internal diameter. CCTA is a noninvasive imaging modality that can precisely delineate the spatial relationship of the coronary artery anatomy. During CCTA imaging acquisition, patients were asked to hold their breath. Simultaneously, iodine contrast agent and normal saline, according to the patient's weight, were injected through two high-pressure syringes at a speed of $5.0 \mathrm{ml} / \mathrm{s}$. The bolus tracking technique was used to detect the threshold of the aortic root. CCTA imaging was started $5 \mathrm{~s}$ after an attenuation threshold of $>100$ Hounsfield units .

\section{Imaging Analysis}

After imaging acquisition by revolution CT, CCTA imaging reconstruction was performed using a CardIQ Xpress (GE Healthcare, USA). Three imaging modality data were derived from the CCTA: maximum intensity projection, oblique imaging, and volume rendering ; all three parameters showed positive values due to the relationship between the myocardium and the coronary artery. Additionally, coronary stenosis and plaques could be delineated by viewing the coronary artery lumen using axial imaging. CCTA imaging is usually reconstructed in $75 \%$ of the phase of the cardiac cycle, which is at systole; during this period, the lumen of the coronary artery is clearly visible. The CT-FFR values were measured using Shukun-FFR V1.0 (Shukun, China). The CT-FFR value is an important parameter for diagnosing myocardial ischemia. A value of CT-FFR $>0.8$ was considered to be no myocardial ischemia, $0.75<$ CT-FFR $<0.8$ was considered to have no clinical significance, and CT-FFR $<0.75$ was considered to be myocardial ischemia; the smaller the value, the greater the possibility of myocardial ischemia.

\section{Statistical analysis}

Statistical analyses were performed using the IBM commercial software SPSS (Version 25.0, American). Age, MB length, and MB depth are presented as mean \pm SD. The CT-FFR value and artery diameter in the systole and diastole periods are presented as mean ( $95 \%$ confidence interval). The number of dominant coronary artery types and the number of patients with MB according to location were statistically calculated as percentages. Statistical significance was set at $p<0.05$.

\section{Results}

\section{Patients' demographics}

A total of 100 patients with MB of the LCX artery were selected out of the 8375 patients with MB. The demographics are illustrated in Table 1. The mean age of those 100 patients was $57.43 \pm 13.67$ years. The number of males and females were 51 and 49 , respectively. Among the 100 patients, 49 had isolated MB of the LCX artery, but out of 49 patients, 29 were associated with lesion of the coronary artery. Otherwise, the number of right coronary dominance and balance dominance were 80 and 20, respectively; while no left coronary dominance existed in this group. Regarding clinical characteristics, 53 out of 100 patients had a typical chest pain or chest discomfort, 30 had hypertension, and 28 had coronary atherosclerosis. 
Table 1

Clinical characteristics of included LCX and OM MB patients

\begin{tabular}{|lll|}
\hline & LCX MB (n=17) & OM MB ( $\mathbf{n}=5)$ \\
\hline Age (mean \pm SD) & $52.22 \pm 12.17$ & $68 \pm 8.67$ \\
\hline Sex (male) & $6(35.29 \%)$ & 0 \\
\hline MB length (mean \pm SD) & $2.82(2.20-3.43)$ & $3.10(1.15-5.05)$ \\
\hline MB depth (mean \pm SD) & $0.24(0-0.49)$ & $0.24(0.19,0.28)$ \\
\hline CT-FFR in proximal to MB & $0.96(0.96-0.97)$ & $0.96(0.96-0.97)$ \\
\hline CT-FFR in distal to MB & $0.93(0.92-0.94)$ & $0.93(0.91-0.96)$ \\
\hline Arrhythmia & $3(17.64 \%)$ & 0 \\
\hline hypertension & $3(17.64 \%)$ & $2(40 \%)$ \\
\hline Chest pain and chest discomfort & $6(35.29 \%)$ & $1(20 \%)$ \\
\hline ECG abnormal & $9(47.37 \%)$ & $3(60 \%)$ \\
\hline Right Coronary dominance & $12(70.59 \%)$ & $5(100 \%)$ \\
\hline Left Coronary dominance & 0 & 0 \\
\hline Co-dominant coronary & $6(29.41 \%)$ & 0 \\
\hline Deep MB & $1(5.88 \%)$ & 0 \\
\hline Superficial MB & $16(94.12 \%)$ & $5(100 \%)$ \\
\hline
\end{tabular}

To explore the demographics and clinical features of isolated MB of the LCX artery, a total of 23 patients (mean age, $55.65 \pm 13.28$ years) with bridging of the LCX artery were enrolled for the study. Among them, 17 patients with MB of the LCX artery, 5 with MB of the OM artery, and 1 with bridging of both the LCX and OM arteries were enrolled in the study. Further, a patient associated with the abnormal arising LCX artery from the right sinus and bridging of the OM. In addition, 23 patients (mean age: $55.65 \pm 13.28$ years) with MB of the LAD artery and 10 patients (mean age: $53.10 \pm 11.06$ years) with MB of the right coronary artery were selected in the control group. The demographics are illustrated in Table 2. The number of patients with chest pain or chest discomfort were 18 (18/23, 78.26\%), 17 (17/23, 73.91\%), and 7 (7/10, $70 \%)$, respectively. There is no significant difference of the number of chest discomfort between the three groups. The Left coronary artery dominance was not observed in these groups. The $95 \% \mathrm{Cl}$ of the thickness and length of bridging segment in three groups were: (LCX: 0.24 $[0.05,0.43]$ vs. LAD: $1.34[-0.53,3.21]$ vs. RCA $0.64[0.23,1.05])$ and (LCX: 2.88 [2.32, 3.42] vs. LAD: 2.19 [1.68, 2.69] vs. RCA 2.57 [1.55, 3.60]), respectively. The $95 \% \mathrm{Cl}$ of CT-FFR in the proximal and distal segments of bridging of the three groups were: (LCX: 0.96 [0.96, 0.97] vs. LAD: $0.93[0.91,0.95]$ vs. RCA 0.95 [0.92, 0.97]) and (LCX: 0.93 [0.92, 0.94] vs. LAD: $0.89[0.86,0.92]$ vs. RCA 0.89 [0.87, 0.93]), respectively. In addition, abnormal ECG findings were present in more than half of the patients with MB (LAD artery MB, 60.87\% [14/23] vs. LCX artery MB, $52.17 \%$ [12/23] vs. RCA MB, 50\% [5/10]). MB in the LAD and RCA are mostly located in the middle segments (21/23 vs $7 / 10)$; but MB in the LCX artery is mostly located in the distal segments $(22 / 23)$. 
Table 2

Characteristics of MB in the LCX, RCA, and LAD

\begin{tabular}{|c|c|c|c|c|c|}
\hline & & LAD MB(n= 23) & $\mathrm{LCX} M B(n=23,24$ bridging segments) & $\operatorname{RCA} M B(n=10)$ & $p$ value \\
\hline \multicolumn{2}{|l|}{ age } & $55.65 \pm 12.97$ & $55.65 \pm 12.97$ & $54.1 \pm 10.49$ & $P>0.05$ \\
\hline \multicolumn{2}{|l|}{ Sex (male: female) } & $6: 17$ & $6: 17$ & $8: 2$ & \\
\hline \multicolumn{2}{|l|}{ hypertension } & 1 & 5 & 1 & \\
\hline \multicolumn{2}{|c|}{ Chest pain or chest discomfort } & $73.91 \%(17 / 23)$ & $78.26 \%(18 / 23)$ & $70 \%(7 / 10)$ & $P>0.05$ \\
\hline \multirow[t]{3}{*}{ Coronary dominant } & left & 0 & 0 & 0 & \\
\hline & balance & 0 & 6 & 2 & \\
\hline & right & 23 & 17 & 8 & \\
\hline \multicolumn{2}{|l|}{ ECG abnormal (n) } & $60.87 \%(14 / 23)$ & $52.17 \%(12 / 23)$ & $50 \%(5 / 10)$ & \\
\hline \multirow[t]{3}{*}{ MB location } & proximal & 0 & 1 & 2 & \\
\hline & middle & 23 & 1 & 7 & $P<0.001$ \\
\hline & distal & 2 & 22 & 1 & $P<0.001$ \\
\hline \multirow[t]{2}{*}{ MB type } & deep & 2 & 1 & 0 & \\
\hline & superficial & 21 & 23 & 10 & $P>0.05$ \\
\hline
\end{tabular}

More importantly, we demonstrated the CCTA performance of different types of MB (Fig. 2 to Fig. 5). Through VR and oblique reconstruction, we clearly observed the course of the coronary artery, its relationship with myocardial tissue, and the condition inside the coronary lumen, such as the presence of plaque, stenosis, and/or obstruction.

\section{Discussion}

Our study is the first study to investigate the clinical features and morphological characteristics of patients with MB of the LCX artery. We found that MB of the LCX artery was mostly located on the distal segment, and mostly MB of the LCX artery is superficial, long bridging, and non-left coronary dominant. Patients with bridging in the LCX artery are usually associated with chest discomfort and abnormal ECG, but with a normal CT-FFR value, which is different from the study results [15]. Coronary atherosclerosis did not occur in patients with MB of the LCX artery.

MB was discovered by Reyman through an autopsy in 1737 and was first described by Geringer in 1951 through coronary angiography [16, 17]. It has been proved to have a systole "Milk-effect" phenomenon and can result in a change in the hemodynamics of the bridging segment artery [18]. In 1960, Portsman and Iwig described it angiographically as a transient narrowing of the coronary artery during systole [19]. Furthermore, MB can lead to severe cardiac events such as myocardial ischemia, angina, myocardial infarction, and sudden death.

The LCX artery is one of the three major branches of the coronary artery, and it mainly supplies the left ventricular lateral wall and posterior wall of the heart. However, very few original papers mentioned MB of the LCX artery, but did not describe it in detail [20-26]. Furthermore, several researchers have reported case reports stating the characteristics of MB of the LCX artery[7-14]. Even though most MBs are considered congenital and asymptomatic, most cases have reported that patients with MB of the LCX artery experienced severe and chronic chest pain [79,11-14]. In 2005, Gunduz et al. first described a case of myocardial infarction in the first OM of the LCX artery [9]. Aksoy et al. reported that asymptomatic MB cases showed $100 \%$ systolic narrowing and incidentally presented with acute coronary syndrome [11]. A few reports on MB involving the LCX artery are shown in Table 3. MB involving the LCX artery may also be associated with changes in the ECG (7,8,10,12,13, angina [8], acute coronary syndrome, and severe cardiac events [12]. Published case reports suggest that ST-segment changes are the main changes in patients with MB of the LCX artery $[8,10,13]$. 
Table 3

Summarizing publishes of MB of LCX

\begin{tabular}{|c|c|c|c|c|c|c|c|c|c|c|}
\hline & $\begin{array}{l}\text { Study } \\
\text { year }\end{array}$ & $\begin{array}{l}\text { Study } \\
\text { type }\end{array}$ & $\begin{array}{l}\text { Imaging } \\
\text { examination } \\
\text { methods }\end{array}$ & age & $\operatorname{sex}$ & hypertensive & Smoking & $\begin{array}{l}\text { Clinical } \\
\text { findings }\end{array}$ & ECG & $\begin{array}{l}\text { Other } \\
\text { characteristics }\end{array}$ \\
\hline 1 & $\begin{array}{l}\text { Grag et } \\
\text { al } \\
2000[5]\end{array}$ & $\begin{array}{l}\text { Case } \\
\text { report }\end{array}$ & $\begin{array}{l}\text { Coronary } \\
\text { angiography }\end{array}$ & 35 & male & no & yes & $\begin{array}{l}\text { Atypical } \\
\text { chest pain } \\
\text { for } 17 \\
\text { years }\end{array}$ & $\begin{array}{l}\text { R wave } \\
\text { poor } \\
\text { progression } \\
\text { and T } \\
\text { waves } \\
\text { inversion }\end{array}$ & unknown \\
\hline 2 & $\begin{array}{l}\text { Okmen } \\
\text { et al } \\
2002[6]\end{array}$ & $\begin{array}{l}\text { case } \\
\text { report }\end{array}$ & $\begin{array}{l}\text { Coronary } \\
\text { angiography }\end{array}$ & 45 & male & yes & yes & $\begin{array}{l}\text { Chest pain } \\
\text { to the left } \\
\text { shoulder } \\
\text { on exertion } \\
\text { for the last } \\
4 \text { months }\end{array}$ & $\begin{array}{l}\text { ST-segment } \\
\text { depression }\end{array}$ & $\begin{array}{l}\text { exercise- } \\
\text { induced } \\
\text { angina } \\
\text { pectoris; }\end{array}$ \\
\hline 3 & $\begin{array}{l}\text { Gunduz } \\
\text { et al } \\
2005[7]\end{array}$ & $\begin{array}{l}\text { letter } \\
\text { to the } \\
\text { editor }\end{array}$ & $\begin{array}{l}\text { Coronary } \\
\text { angiography \& } \\
\text { echocardiographic }\end{array}$ & 54 & male & no & unknown & $\begin{array}{l}\text { chest pain } \\
\text { and } \\
\text { progressive } \\
\text { dyspnea }\end{array}$ & unknown & $\begin{array}{l}\text { Myocardial } \\
\text { bridging in the } \\
\text { obtuse } \\
\text { marginal } \\
\text { branch of LCX }\end{array}$ \\
\hline 4 & $\begin{array}{l}\text { Tuncer } \\
\text { et al } \\
2008[8]\end{array}$ & $\begin{array}{l}\text { case } \\
\text { report }\end{array}$ & $\begin{array}{l}\text { Coronary } \\
\text { angiography }\end{array}$ & 63 & male & no & no & $\begin{array}{l}\text { Chest pain } \\
\text { radiating to } \\
\text { the left } \\
\text { shoulder }\end{array}$ & $\begin{array}{l}\text { ST-segment } \\
\text { changes }\end{array}$ & $\begin{array}{l}\text { A significant } \\
\text { systolic } \\
\text { narrowing on } \\
\text { the mid-LCX }\end{array}$ \\
\hline 5 & $\begin{array}{l}\text { Peters S } \\
2019[9]\end{array}$ & $\begin{array}{l}\text { letter } \\
\text { to the } \\
\text { editor }\end{array}$ & $\begin{array}{l}\text { Coronary } \\
\text { angiography }\end{array}$ & 38 & female & unknown & unknown & Chest pain & unknown & unknown \\
\hline 6 & $\begin{array}{l}\text { Aksoy et } \\
\text { al } \\
2017[10]\end{array}$ & $\begin{array}{l}\text { case } \\
\text { report }\end{array}$ & $\begin{array}{l}\text { Coronary } \\
\text { angiography }\end{array}$ & 62 & male & no & yes & $\begin{array}{l}\text { Severe, } \\
\text { squeezing } \\
\text { chest pain }\end{array}$ & $\begin{array}{l}\text { T wave } \\
\text { inversion } \\
\text { and R wave } \\
\text { progression }\end{array}$ & unknown \\
\hline 7 & $\begin{array}{l}\text { Ibarrola } \\
\text { et al } \\
2019[11]\end{array}$ & $\begin{array}{l}\text { case } \\
\text { report }\end{array}$ & Coronary CTA & 54 & female & unknown & unknown & unknown & $\begin{array}{l}\text { ST } \\
\text { depression }\end{array}$ & $\begin{array}{l}\text { LCX arising } \\
\text { from right } \\
\text { sinus ostium }\end{array}$ \\
\hline 8 & $\begin{array}{l}\text { Kiris et } \\
\text { al } \\
2016[12\end{array}$ & $\begin{array}{l}\text { Case } \\
\text { report }\end{array}$ & Coronary CTA & 46 & male & unknown & unknown & $\begin{array}{l}\text { With } \\
\text { recurrent } \\
\text { retrosternal } \\
\text { chest pain } \\
\text { of } 3 \\
\text { months } \\
\text { duration }\end{array}$ & unknown & $\begin{array}{l}\text { MB in the LAD, } \\
\text { ramus } \\
\text { intermediate, } \\
\text { and first OM }\end{array}$ \\
\hline
\end{tabular}

Few studies have pointed out that MB located on the proximal segment may easily prolong the development of coronary atherosclerosis and hemodynamic changes $[15,27]$.Therefore, knowing the position of bridging in the coronary artery is vital, as it provides diagnostic information that can guide management of the condition. In this study, the MB of the LCX artery was mostly located at the distal segment and was not associated with atherosclerosis. A study [5] has pointed out that the overall average MB length was $2.02 \mathrm{~cm}$. However, in this study, the $95 \% \mathrm{Cl}$ of the length of bridging segment in LCX, LAD and RCA groups were, LCX: $2.88(2.32,3.42), 2.19(1.68,2.69), 2.57(1.55,3.60)$. In this study, we observed that bridging segments in the LCX artery were longer than that in the other arterial branches.

In this study, almost 70\% patients with MB were associated with chest pain or discomfort for a long time, but all CT-FFRs were normal even in patients with chest discomfort or chest pain. The $95 \% \mathrm{Cl}$ of CT-FFR in the proximal segment of bridging of the three groups were, LCX: 0.96 $(0.96,0.97)$, LAD: $0.93(0.91,0.95)$, and RCA $0.95(0.92,0.97)$, respectively. Further, the $95 \% \mathrm{Cl}$ of CT-FFR in the distal segment of bridging of the three groups were LCX: $0.93(0.92,0.94)$, LAD: $0.89(0.86,0.92)$, RCA $0.89(0.87,0.93)$, respectively; with no significant difference between the three groups. This result may be related to the data inclusion criterion which only enrolled patients with isolated MB. Moreover, in most patients, MB of the superficial type was present.

However, most patients presented with chest pain and abnormal ECG was observed even in patients with superficial and normal hemodynamics, which is independent of the location of the MB. In this study, abnormal ECG findings were present in more than half of the patients with MB (LAD artery MB, 60.87\% [14/23] vs. LCX artery MB, 52.17\% [12/23] vs. RCA MB, 50\% [5/10]). 
Coronary artery dominance depends on the origin of the posterior descending artery, which supplies blood to the posterior portion of the interventricular septum [28-30]. There are three types of coronary artery dominance: right, co-dominant, and left. The right coronary dominant heart was defined as the posterolateral portion arising from the right coronary artery, and the left coronary dominant heart was defined as the posterior descending artery arising from the LCX artery [29]. It has been found that about $80-85 \%$ of the coronary arteries present a rightdominant pattern [31]. The coronary artery tree with different coronary artery dominance was reconstructed based on CCTA, as shown in Fig. 6. All the enrolled patients were found to have right dominant or co-dominant hearts, and no left dominant hearts were found. There are two reasons for this phenomenon. First, the right dominant and co-dominant heart commonly exist in the human heart, and MB involving the LCX artery is a rare cardiovascular disease. Second, in the left dominant heart, the LCX artery is the main coronary artery supplying the interventricular septum. Therefore, this phenomenon may be explained as an evolutionary occurrence as the heart and MB are congenital diseases. However, there was no left dominant heart in patients with MB of the RCA; but, its pathophysiology remains unknown.

\section{Limitation}

There exist few limitations in our study. MB involving the LCX artery is a rare disease, and the number of patients in the study group was small. Some biases may exist because all cases in this study underwent CCTA for chest discomfort, and were otherwise asymptomatic. There are no follow up data in this study.

\section{Conclusions}

MB of the LCX artery were mostly located in the mid-segment of LCX artery and mostly present superficially and was long bridging. The CT-FFR were normally present in isolated MB of the LCX artery. If a patient presents with chest discomfort, chest pain, and other cardiac symptoms, CCTA should be performed to check the condition of the coronary artery irrespective of a history of hypertension. Bridging of the LCX artery is longer than that of the other coronary arteries. CT-FFR has a false result in the measurement on MB in patients with chest pain or chest discomfort.

\section{Declarations}

\section{Acknowledgments}

This work was supported by 2020 New Interdisciplinary Construction Project of Shanghai Pudong New Area Health [PWXx2020-06] and Hospital Research Foundation from Shanghai University of Medicine \& Health Sciences affiliated Zhoupu Hospital [ZPXM-2019A-12]

\section{References}

1. Cerit L, Duygu H (2017) Myocardial bridging and sudden death. Int J Cardiol 229. https://doi.org/11.1016/j.ijcard.2016.11.308

2. Teragawa H, Oshita C, Ueda T (2019) The Myocardial bridge: Potential Influences on the Coronary Artery Vasculature. Clin Med Insights Cardiol13:1179546819846493.https://doi.org/1177/1179546819846493

3. Berry JF, von Mering GO, Schmalfuss C, Hill JA, Kerensky RA (2002) Systolic compression of the left anterior descending coronary artery: a case series, review of the literature, and therapeutic options including stenting. Catheter Cardiovasc Interv 56:5863.https://doi.org/1002/ccd.10151

4. Morales AR, Romanelli R, Boucek RJ (1980) The mural left anterior descending coronary artery, strenuous exercise and sudden death. Circulation 62:230-237.https://doi.org/1161/01.cir.62.2.230

5. Murtaza G, Mukherjee D, Gharacholou SM, Nanjundappa A, Lavie CJ, Khan AA, Shanmugasundaram M, Paul TK (2020) An Updated Review on Myocardial Bridging. Cardiovasc RevascMed 21:1169-1179. https://doi.org/1016/j.carrev.2020.02.014

6. Soberts W, Charles SM, Ang C, Holda MK, Walocha J, Lachman N, Tubbs RS, Loukas M (2021) Myocardial bridges: A meta-analysis. Clin Anat 34:685-709. https://doi.org/1002/ca.23697

7. Garg S, Brodison A, Chauhan A (2000) Occlusive systolic bridging of circumflex artery. Catheter Cardiovasc Interv. 51:477-478. https://doi.org/1002/1522-726x(200012)51:4<477::aid-ccd22>3.0.co;2-k

8. Okmen E, Oguz E, Erdinler I, Sanli A, Cam N (2002) Left circumflex coronary artery bridging. Jpn Heart J43:423427.https://doi.org/1536/jhj.43.423

9. Gunduz H, Akdemir R, Tataroglu C, Albayrak S, Erbilen E, Akdemir N, Yilmaz H, Uyan C (2005) Myocardial bridging of obtuse marginal branch of the left circumflex artery associated with congenital corrected transposition of the great arteries. Int J Cardiol98:503505.https://doi.org/1016/j.ijcard.2003.10.033 
10. Tuncer C, Sökmen G, Acar G, Köroğlu S (2008) A case of myocardial bridging of the left circumflex coronary artery. Turk Kardiyol Dern Ars 36:562-563.

11. Peters S 0 Unusual case of myocardial bridging of the circumflex artery and initially intractable chest pain. Int J Cardiol 179:2526.https://doi.org/10.1016/j.ijcard.2015.04.137

12. Aksoy F, Baş HA, Altınbaş A (2018) Nonsymptomatic myocardial bridge causing systolic total narrowing of circumflex artery. J Saudi Heart Assoc 30:153-156.https://doi.org/1016/j.jsha.2017.06.002

13. Ibarrola M (2020) Anomalous origin of left circumflex artery, myocardial bridges and myocardial ischemia. J Cardiovasc ComputTomogr14:e85-e86.https://doi.org/1016/j.jcct.2019.06.012

14. Kiris T, Koprulu D, Elmali M, Zeren G, Erdogan G (2016) A rare case of myocardial bridge involving left anterior descending, obtuse marginal and ramus intermediate coronary arteries. KardiochirTorakochirurgia Pol 13:368-369.https://doi.org/5114/kitp.2016.64886

15. Zhou F, Tang CX, Schoepf UJ, et al (2019) Fractional flow reserve derived from CCTA may have a prognostic role in myocardial bridging. Eur Radiol 29:3017-3026. https://doi.org/10.1007/s00330-018-5811-6

16. Geiringer E (1951) The mural coronary. Am Heart J 41:359-368.https://doi.org/10.1016/0002-8703(51)90036-1

17. Reyman HC (1737) Disertatio de vasis cordis propriis. BiblAnat 2:359-379.

18. Mookadam F, Green J, Holmes D, Moustafa SE, Rihal C (2009) Clinical relevance of myocardial bridging severity: single center experience. Eur J Clin Invest9:110-115.https://doi.org/1111/j.1365-2362.2008.02073.x

19. Portsmann W, Iwig J (1960) Die intramuraleKoronarieimAngiogramm. Fortschr Geb RontgenstrNuklearmed 92:129-132.

20. Aydar Y, Yazici HU, Birdane A, Nasifov M, Nadir A, Ulus T, Göktekin O, Gorenek B, Unalir A (2011) Gender differences in the types and frequency of coronary artery anomalies. Tohoku J Exp Med 225:239-247.https://doi.org/1620/tjem.225.239

21. Cay S, Ozturk S, Cihan G, Kisacik HL, Korkmaz S (2006) Angiographic prevalence of myocardial bridging. Anadolu KardiyolDerg 6:9-12.

22. Atar E, Kornowski R, Fuchs S, Naftali N, Belenky A, Bachar GN (2007) Prevalence of myocardial bridging detected with 64-slice multidetector coronary computed tomography angiography in asymptomatic adults. J Cardiovasc ComputTomogr 1:78-83. https://doi.org/1016/j.jcct.2007.08.003

23. Chen YD, Wu MH, Sheu MH, Chang CY (2009) Myocardial bridging in Taiwan: depiction by multidetector computed tomography coronary angiography. J Formos Med Assoc 108:469-474. https://doi.org/1016/S0929-6646(09)60094-2

24. Mavi A, Sercelik A, Ayalp R, Karben Z, Batyraliev T, Gumusburun E (2008) The angiographic aspects of myocardial bridges in Turkish patients who have undergone coronary angiography. Ann Acad Med Singap 37:49-53.

25. Teofilovski-Parapid G, Jankovic R, Kanjuh V, Virmani R, Danchin N, Prates N, Simic DV, Parapid B (2017) Myocardial bridges, neither rare nor isolated-Autopsy study. Ann Anat 210:25-31. https://doi.org/1016/j.aanat.2016.09.007

26. Liu G, Qu Y, Chen X, Liao M, Hu H, Cao Y, Tian Z (2017) Measurements of myocardial bridges on computed tomography predict presence of clinical symptoms and outcomes of adverse heart events: a retrospective study in a large population from China. Acta Radiol58:10681076. https://doi.org/1177/0284185116682380

27. Loukas M, Curry B, Bowers M, Louis Jr RG, Bartczak A, Kiedrowski M, Kamionek M, Fudalej M, Wagner T (2006) The relationship of myocardial bridges to coronary artery dominance in the adult human heart. J Anat 209:43-50. https://doi.org/1111/j.14697580.2006.00590.x

28. Ajayi NO, Vanker EA, Satyapal KS (2017) Coronary artery dominance dependent collateral development in the human heart. Folia Morphol 76:191-196.https://doi.org/5603/FM.a2016.0051

29. Gebhard C, Gick M, Ferenc M, Stähli BE, Ademaj F, Mashayekhi K, Buettner HJ, Neumann FJ, Toma A (2018) Coronary dominance and prognosis in patients with chronic total occlusion treated with percutaneous coronary intervention. Catheter Cardiovasc Interv 91:669-678. https://doi.org/1002/ccd.27174

30. Allwork SP (1987) The applied anatomy of the arterial blood supply to the heart in man. J Anat 153:1-16.

31. Anderson JL, Morrow DA (2017) Acute Myocardial Infarction. N Engl J Med 376:2053-2064.https://doi.org/1056/NEJMra1606915

\section{Figures}




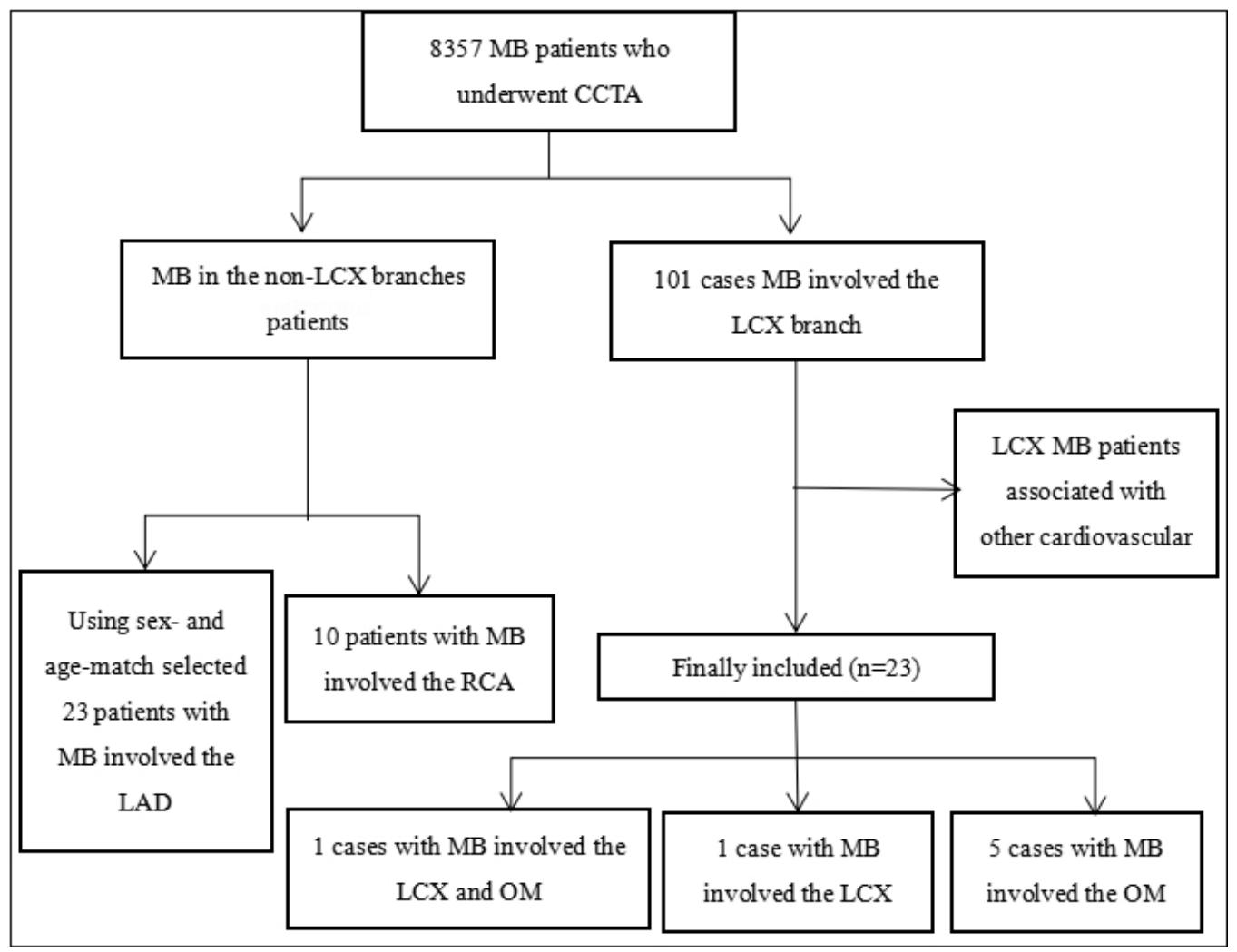

\section{Figure 1}

Flow chart of inclusion and exclusion. MB, myocardial bridging; CCTA, coronary computed tomography angiography; LCX, left circumflex artery; $\mathrm{OM}$, obtuse marginal branch; LAD: left anterior descending coronary artery; RCA: right coronary artery
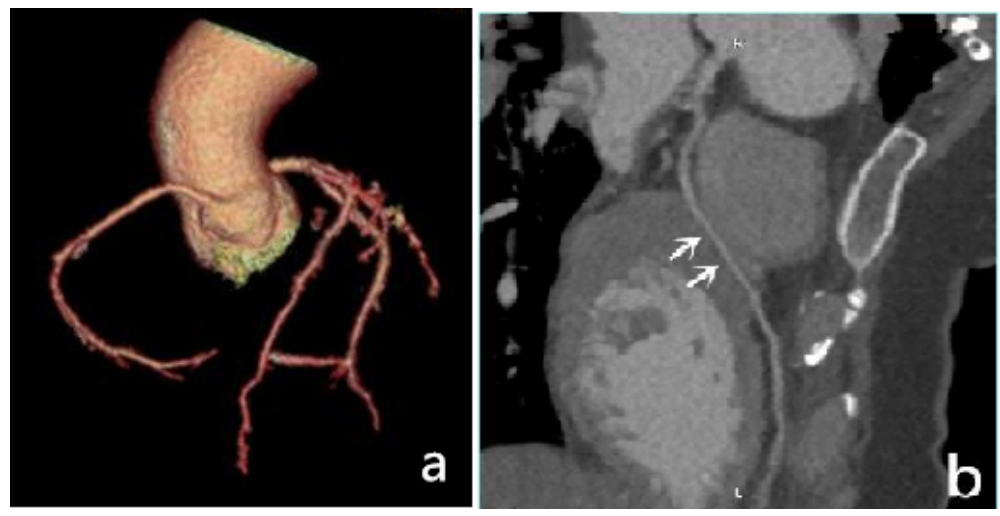

Figure 2

A 42 years old woman with chest pain for a long time but ECG was present normal. Right coronary dominance. Patient with deep MB at the middle segment of LAD (white arrow) and without atherosclerosis and other cardiovascular diseases. a: VR of coronary artery tree; b: An oblique image of the LAD. 


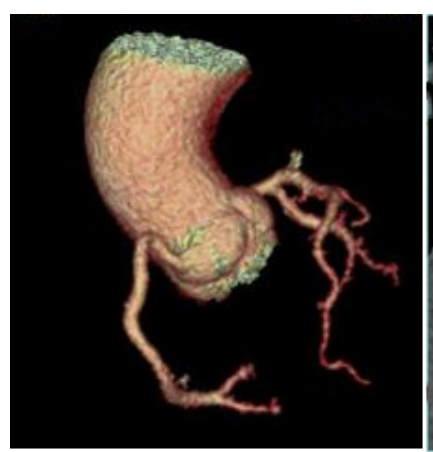

1a

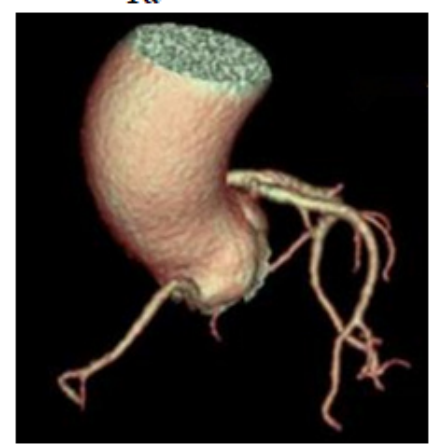

$2 a$

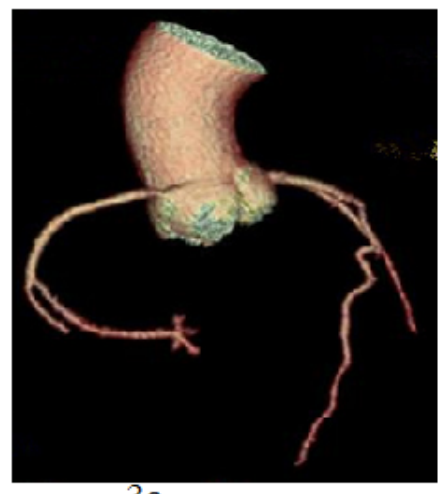

$3 a$

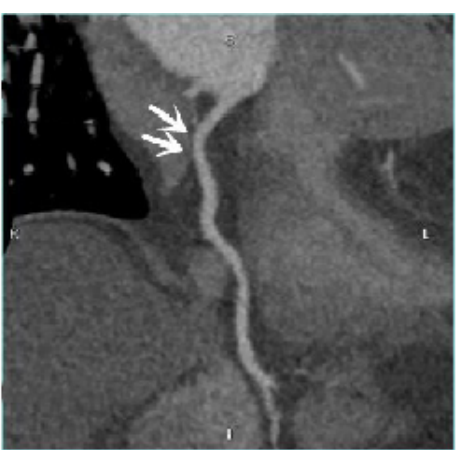

$1 b$

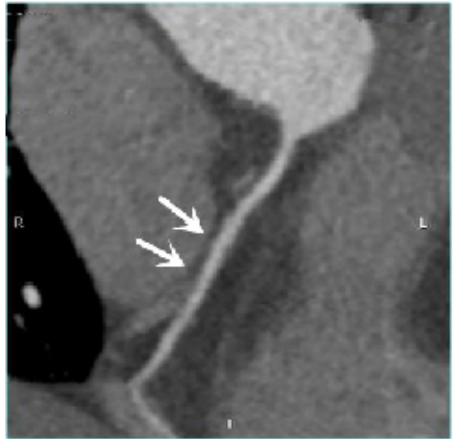

$2 \mathrm{~b}$

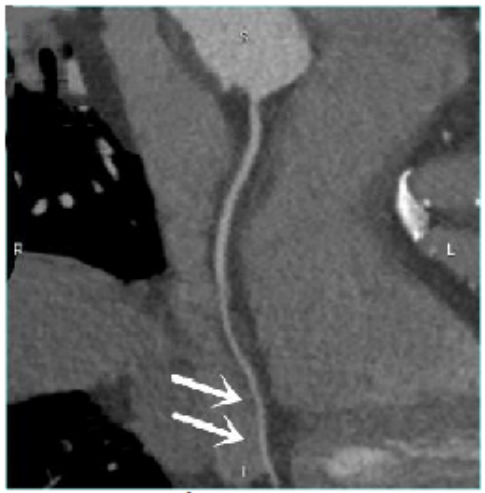

$3 \mathrm{~b}$

\section{Figure 3}

Image of $\mathrm{MB}$ involving the RCA. a row: $\mathrm{A} 58$ years old male with dizzy but ECG normal, right coronary dominance, with MB in the proximal segment of RCA (white arrow); brow: A 59 years old female with chest pain but ECG normal, right coronary dominance, patients with MB in the middle segment of RCA (white arrow); c row: A 67 years old male with chest discomfort and T wave abnormal, right coronary dominance, with $\mathrm{MB}$ in middle distal of RCA (white arrow). The first column is the volume rendering imaging of the coronary artery tree; the second column is the oblique image of the right coronary artery. 


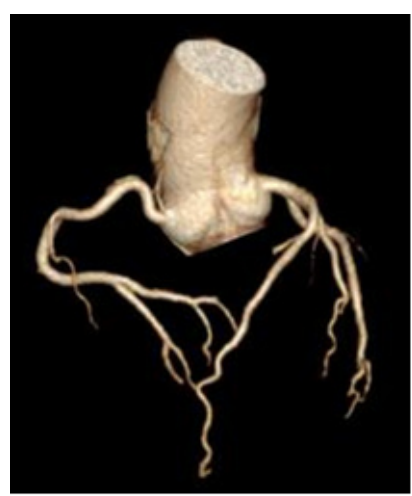

1a

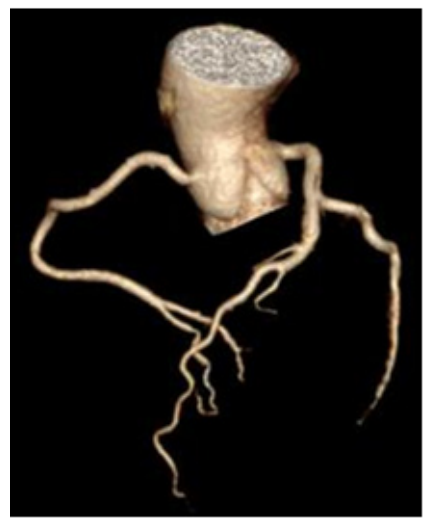

$2 a$

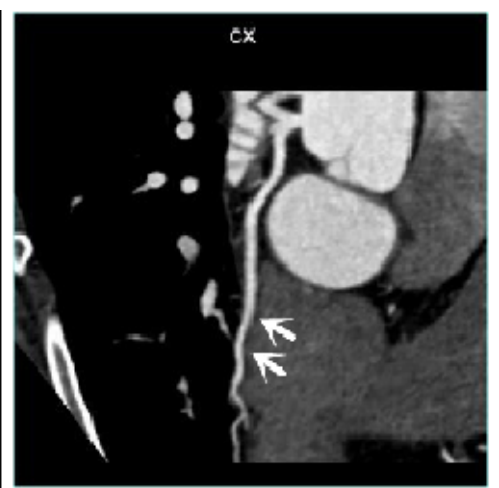

$1 \mathrm{~b}$

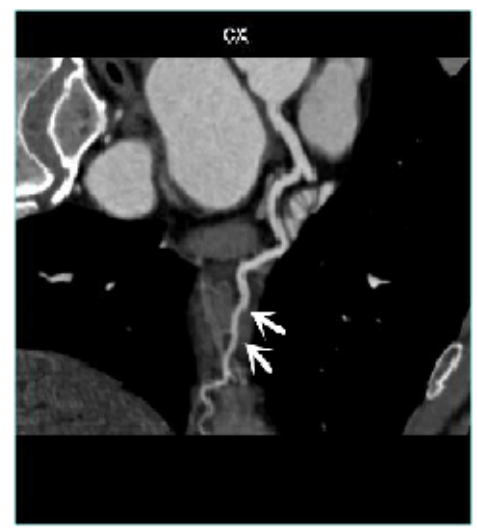

$2 b$

\section{Figure 4}

MB of LCX. a: a 50 years old male with hypertension and chest discomfort but the ECG presents normal. CTA image showed a superficial MB of the middle segment of LCX (white arrow) and the right dominant heart. b: a 52 years old female with hypertension and chest discomfort but the ECG presents normal. CTA image showed a deep MB of the distal segment of LCX (white arrow) and right dominant heart. The first column is the volume rendering imaging of the coronary artery tree; the second column is the oblique image of the right coronary artery.
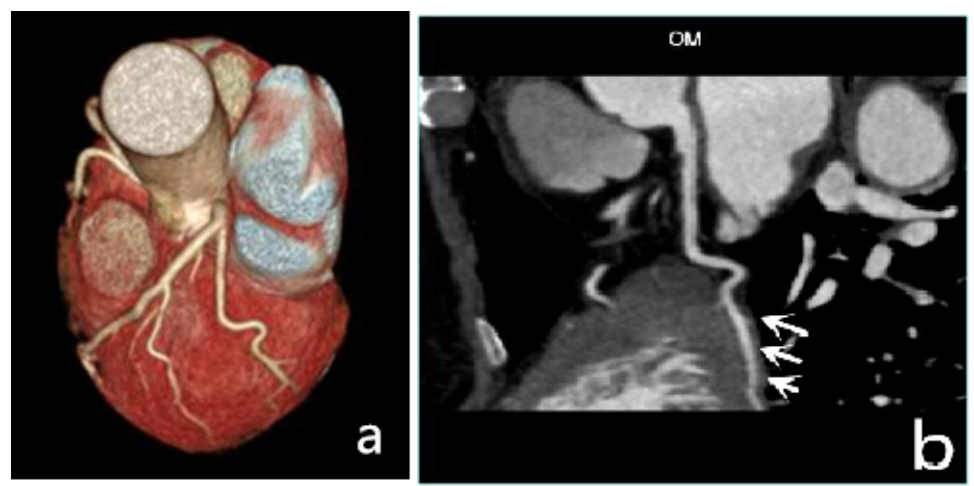

Figure 5

A 70 years old female with hypertension and underwent CCTA because of chest discomfort. And the examination result illustrates this patient with $\mathrm{MB}$ in the middle segment of the OM branch (white arrow). And the LCX of these patients is absent. a is the volume rendering image of the heart; $b$ is the second is the oblique image of OM. 

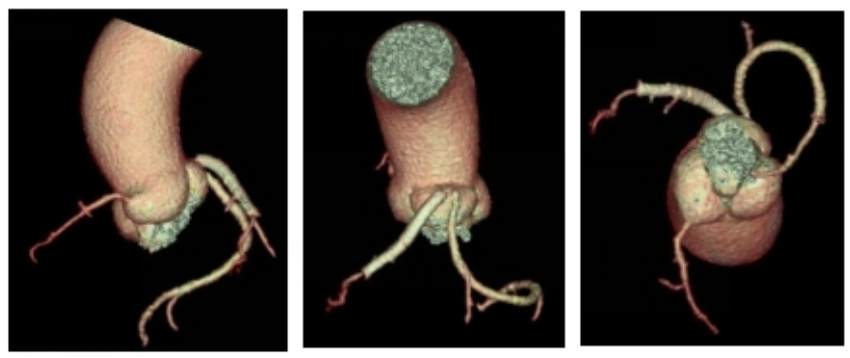

Left coronary

dominance
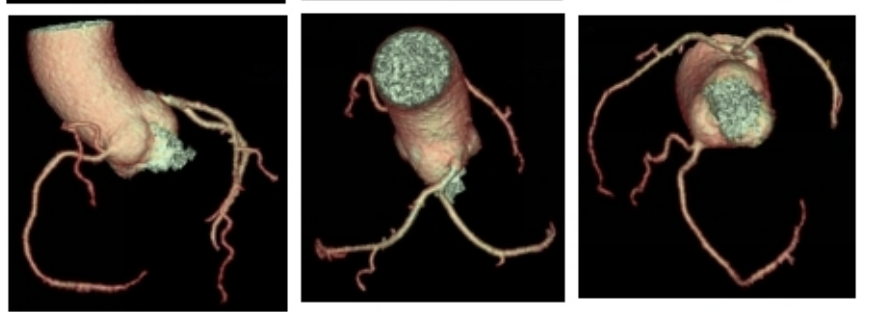

Balance coronary

dominance
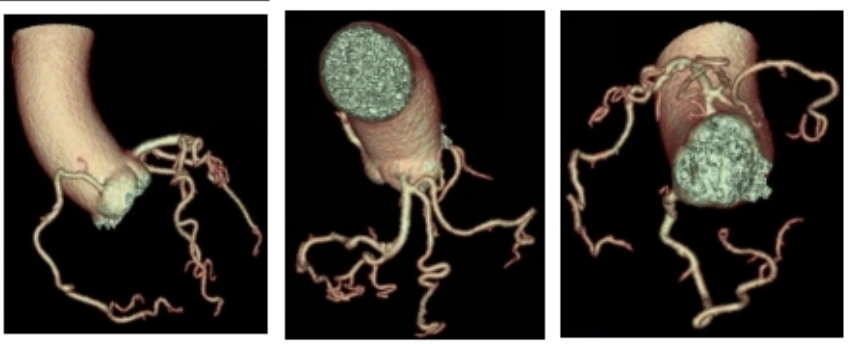

Right coronary

dominance

Figure 6

The volume rendering imaging of coronary artery tree of three dominant coronary heart 